\title{
ACCULTURATION VARIETY OF SUNDANESSE AND MODERN ARCHITECTURE AT SELASAR SUNARYO ART SPACE IN BANDUNG
}

\author{
${ }^{1}$ Gabriella Serena. ${ }^{2}$ Dr. Ir. Bachtiar Fauzy, M.T. \\ ${ }^{1}$ Student in the Bachelor's (S-1) Study Program in Architecture \\ at Parahyangan Catholic University \\ ${ }^{2}$ Senior lecturer in the Bachelor's (S-1) Study Program in Architecture \\ at Parahyangan Catholic University
}

\begin{abstract}
The growth of globalization is a worldwide phenomenon that is unavoidable and its impact affects a lot of fields, including architecture. Non-local elements, like modernism, that penetrate Indonesia's culture cause a competition against the local architecture including traditional values, which are reduced due to modernization. Combining modern and local architecture can be seen as an effort to conserve traditional values and answer to the era's challenge at the same time through the application of modernization.

The aim of this research is to understand the meaning of acculturation in architecture, discover which acculturation that occurs in Selasar Sunaryo Art Space architecture and discover what domination that exists in Selasar Sunaryo Art Space's architecture.

Study of synthesis of architecture in Selasar Sunaryo Art Space is done by doing firstly a survey to gain object data, undertake an interview with the architect and client to gain the architectural concept of the object, and re-model the object in 3D. Literature is also done to gain theories about acculturation in architecture, building anatomy theory to describe the study object, also Sundanese and modern architecture theories. Afterwards, the object is analyzed by the said theories and interpreted referring to literature.

The result of this research shows that modern architecture dominates Selasar Sunaryo's architecture, especially in it's body, floor, structure, and 's shape. Synthesis of architecture can be seen from the landscape design and roof design. Overall, Selasar Sunaryo's architecture is dominated by modern structure and arrangements, although there are several adaptations to the building's climate context and application of Sundanese architecture concepts to its buildings.

Hopefully this thesis would be beneficial to practitioners, academics, and people in general as a contribution to expand the knowledge of local and non-local architecture synthesis, also as a contribution of knowledge that is beneficial within designing process or of continuation of the research.
\end{abstract}

Key Words: acculturation, architecture, modern, Sundanese

\section{RAGAM AKULTURASI ARSITEKTUR SUNDA DAN MODERN PADA SELASAR SUNARYO ART SPACE DI BANDUNG}

\author{
${ }^{1}$ Gabriella Serena. ${ }^{2}$ Dr. Ir. Bachtiar Fauzy, M.T. \\ ${ }^{1}$ Mahasiswa S1 Program Studi Arsitektur Universitas Katolik Parahyangan \\ ${ }^{2}$ Dosen Pembimbing S1 Program Studi Arsitektur Universitas Katolik Parahyangan
}

\begin{abstract}
Abstrak- Perkembangan globalisasi merupakan fenomena mendunia yang tidak terhindarkan dan dampaknya memengaruhi berbagai bidang, termasuk arsitektur. Unsur-unsur arsitektur non-lokal, salah satunya modernisme yang masuk dengan mudah ke Indonesia menyebabkan terjadinya persaingan dengan arsitektur lokal, di antaranya
\end{abstract}

${ }^{1}$ Corresponding Author: gabrieallaversa@gmail.com 
arsitektur tradisional yang nilai-nilai arsitektur lokalnya banyak menjadi tereduksi karena tergantikan dengan kemajuan modernisasi. Penggabungan aspek modern dan lokal menjadi penting di era modern dalam menjawab tantangan jaman namun tidak melupakan nilai-nilai lokal.

Tujuan dilakukannya penelitian ini adalah untuk memahami makna akulturasi dalam arsitektur, mengungkap akulturasi arsitektur yang terjadi pada Selasar Sunaryo Art Space, dan mengungkap dominasi arsitektur pada arsitektur Selasar Sunaryo Art Space.

Penelitian dilakukan dengan melakukan survey lapangan untuk memperoleh data objek, melakukan wawancara dengan arsitek dan klien untuk mendapatkan data konsep arsitektur objek, dan penggambaran ulang 3D. Selain itu dilakukan studi literatur untuk memperoleh teori akulturasi dalam arsitektur, teori lingkup dan anatomi bangunan untuk mendeskripsikan objek studi, serta teori langgam arsitektur Sunda dan modern. Setelah itu, objek dianalisa menggunakan teori-teori tersebut kemudian diinterpretasikan sesuai referensi pada literatur.

Dari hasil penelitian, ditemukan adanya dominasi arsitektur modern pada arsitektur Selasar Sunayo, terutama pada bentuk badan, lantai, struktur, dan pada lingkup sosok. Sintesis arsitektur ditunjukkan pada bentuk atap dan pengolahan tapak. Keseluruhan arsitektur Selasar Sunaryo didominasi oleh struktur dan susunan modern, namun terdapat beberapa adaptasi terhadap iklim stempat serta penerapan beberapa konsep arsitektur Sunda pada bangunannya.

Penelitian ini diharapkan bermanfaat bagi para praktisi, akademisi dan masyarakat luas sebagai kontribusi dalam memperluas wawasan mengenai kajian sintesis arsitektur lokal dan lokal serta sumbangan kajian kritis yang bermanfaat dalam merancang maupun melanjutkan penelitian.

Kata Kunci: ragam, akulturasi, arsitektur, Sunda, modern

\section{PENDAHULUAN}

Perkembangan globalisasi di era modern merupakan suatu fenomena yang tak dapat dihindari. Masuknya unsur-unsur non-lokal ke suatu wilayah atau budaya dan terjadi pencampuran unsur lokal dan non-lokal merupakan akibat yang banyak ditemukan dari fenomena ini. Perkembangan ini pun berpengaruh pada dunia arsitektur Indonesia. Akibat mudahnya informasi yang diterima oleh masyarakat luas, banyak unsur non-lokal yang diterapkan pada arsitektur di Indonesia dewasa ini, contohnya modernisme. Namun, penyerapan unsur modern ke dalam arsitektur Indonesia tersebut banyak yang tidak mencerminkan identitas konteks lokal arsitektur tersebut berada. Hasilnya adalah banyaknya adopsi bentuk arsitektur modern namun tidak membawa makna yang terkandung di balik konsep gaya yang ditiru tersebut. Meskipun berkembangnya teknologi modern yang memberikan banyak keuntungan dalam industrialisasi pembangunan serta mudah berkembangnya informasi mengenai tren gaya-gaya baru, nilai-nilai arsitektur lokal di Indonesia menjadi tereduksi. Akibatnya, identitas arsitektur lokal terkikis dan nilai-nilai yang terdapat pada arsitektur lokal banyak yang ditinggalkan. Hal ini menjadi tantangan bagi para arsitek masa kini untuk menjawab tantangan jaman namun tidak melupakan nilai-nilai lokal.

Baskoro Tedjo merupakan seorang arsitek yang masih berusaha menerapkan unsurunsur lokal dalam desainnya. Salah satu karyanya yang menampilkan percampuran antara unsur modernisme dengan unsur tradisional adalah Selasar Sunaryo Art Space, sebuah galeri seni kontemporer yang memiliki keleluasaan dari segi tuntutan fungsi untuk menerapkan suatu gaya arsitektur yang menerima IAI Awards pada tahun 2002 untuk kategori Bangunan Publik dan Budaya. Konsep desain Selasar Sunaryo adalah konsep arsitektur Sunda yang digabungkan dengan arsitektur modern. Hal ini menarik untuk dibahas untuk mempelajari akulturasi pada arsitektur yang tetap mempertahankan konsep arsitektur tradisional dengan gaya modern dalam upaya bertahan dalam arus perkembangan jaman.

Semenjak berkembangnya arsitektur modern di Indonesia, gaya arsitektur tersebut menjadi tren di kalangan masyarakat Indonesia karena dianggap lebih efisien, menggunakan teknologi terkini, dan lebih maju. Hal ini menyebabkan masyarakat lebih banyak yang memilih untuk mengadaptasi gaya arsitektur modern pada bangunan arsitektur di Indonesia, namun 
akibatnya nilai lokalitas pada bangunan tersebut tereduksi. Sementara itu, pembangunan arsitektur tradisional di kehidupan perkotaan modern dianggap sudah tidak relevan karena terbatasnya material tertentu seperti kayu-kayu gelondong, sulitnya transportasi material serta waktu pembangunan yang tidak efisien, padahal arsitektur tradisional membawa nilai-nilai budaya masyarakat Indonesia setempat. Karena itu, penggabungan aspek modern dan tradisional tersebut menjadi penting dalam menjawab tantangan jaman, namun tidak melupakan nilai-nilai lokal.

Pada Selasar Sunaryo Art Space, unsur-unsur arsitektur modern terlihat mendominasi keseluruhan gaya arsitekturnya, sementara konsep arsitektur tradisional yang diangkat pada perancangannya kurang terlihat. Untuk itu diperlukan penelitian ini untuk membuktikan bagaimana akulturasi yang dilakukan pada arsitektur Selasar Sunaryo Art Space untuk mencapai percampuran unsur arsitektur modern dan tradisional yang berintegrasi sehingga mencapai sebuah hasil karya arsitektur yang tetap menerapkan nilai-nilai lokal namun tetap menjawab tantangan jaman.

Penelitian ini dilakukan untuk menjawab pertanyaan; 1) Apa yang dimaksud dengan akulturasi arsitektur pada penelitian ini; 2) Bagaimana akulturasi yang terjadi pada arsitektur Selasar Sunaryo Art Space; dan 3) Apa dominasi arsitektur pada Selasar Sunaryo Art Space.

Aspek telaah penelitian meliputi akulturasi arsitektur yang terdapat pada lingkup tapak serta bangunan objek. Objek studi dideskripsikan menggunakan teori anatomi bangunan, kemudian dibandingkan dengan langgam arsitektur modern dan arsitektur Sunda. Untuk menilai akulturasi arsitektur yang terjadi, analisa dilakukan dengan melihat perbandingan objek dengan referensi arsitektur modern dan Sunda ditinjau dari properti dan susunannya berdasarkan teori bahasa dalam arsitektur.

\section{KAJIAN TEORI}

\subsection{AKULTURASI DALAM ARSITEKTUR}

Menurut Salura (2012 : 149), bentuk akulturasi ada empat, yaitu sinergi, adaptasi, adopsi, dan marginalisasi. Sinergi adalah percampuran budaya lokal dan non-lokal yang sama-sama kuat menghasilkan bentukan yang harmonis. Adaptasi adalah percampuran budya lokal yang kuat dengan budaya non-lokal yang lemah menghasilkan adanya sebagian unsur non-lokal yang diterapkan dalam budaya lokal. Marginalisasi adalah tidak adanya percampuran antara budaya lokal dan non-lokal karena keduanya sama-sama lemah. Adopsi adalah percampuran budaya lokal yang lemah dengan budaya non-lokal yang kuat, menghasilkan adanya banyak unsur non-lokal yang diterapkan dalam budaya lokal.

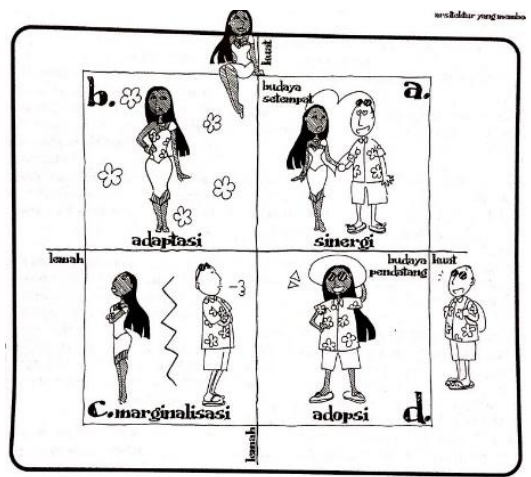

Gambar 2.1. Skema Akulturasi Kebudayaan Sumber : Purnama Salura, 2015 
Berdasarkan uraian diatas, sintesis pada bentuk idealnya merupakan bentuk sinergi sebagai akulturasi paling optimal karena adanya keseimbangan antara unsul lokal dan nonlokal (50\%: 50\%). Adaptasi dan adopsi merupakan bentuk sintesis yang kurang optimal karena salah satu unsur lebih kuat dibanding yang lain sehingga yang tampak adalah salah satu unsur yang lebih dominan (25\%:75\%). Marginalisasi adalah bentuk sintesis yang tidak optimal karena tidak terjadi percampuran antara satu unsur dengan yang lainnya $(0 \%: 0 \%)$.

\subsection{TEORI SUSUNAN DAN PROPERTI}

Pada kuliah Teori Bentuk dan Makna dalam Arsitektur (2016), Purnama Salura menjelaskan bahwa suatu bentuk arsitektur mengandung suatu makna yang dimaknai oleh orang yang melihatnya. Artinya, suatu bentuk arsitektur mengkomunikasikan maknanya melalui mediumnya. Karena arsitektur dapat mengkomunikasikan suatu makna, maka arsitektur memiliki bahasa bentuk. Bahasa bentuk dalam arsitektur ditandai dengan dua komponen, yaitu properti dan susunannya.

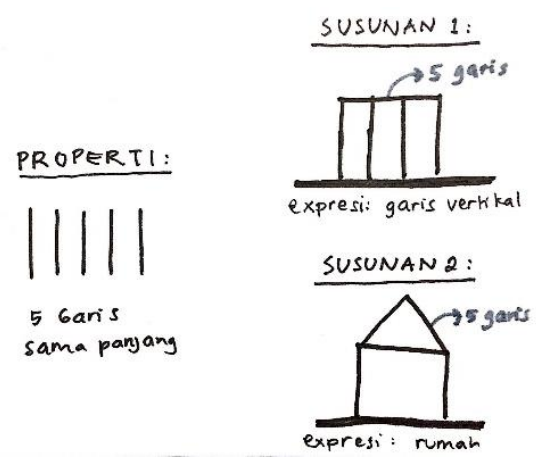

Gambar 2.2. Peran Properti dan Susunan Komponen Arsitektur dalam Menciptakan Ekspresi atau Bahasa Arsitektur.

\subsection{ARSITEKTUR MODERN}

Menurut Bruno Zevi (1978), bahasa arsitektur modern yang anti-klasik dapat diuraikan pada tabel berikut.

Tabel 1. Bahasa Arsitektur Modern Menurut Bruno Zevi

\begin{tabular}{|c|c|c|c|c|}
\hline No. & Konsep & Elemen & Deskripsi & Ilustrasi \\
\hline \multirow[t]{3}{*}{1.} & \multirow{3}{*}{$\begin{array}{l}\text { Listing as Design } \\
\text { Methodology }\end{array}$} & Straight lines & Penggunaan elemen garis yang tegas. & \\
\hline & & $\begin{array}{l}\text { Free Design } \\
\text { Windows }\end{array}$ & $\begin{array}{l}\text { Susunan jendela secara estetis pada } \\
\text { fasad tidak perlu order yang terlalu } \\
\text { membatasi seperti struktur, tetapi } \\
\text { tetap mempertimbangkan } \\
\text { fungsionalitas. }\end{array}$ & 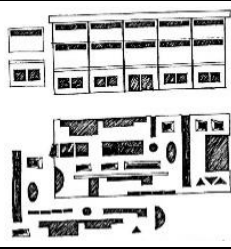 \\
\hline & & $\begin{array}{l}\text { Free Form } \\
\text { Volumes }\end{array}$ & $\begin{array}{l}\text { Bentuk massa tidak perlu terlalu } \\
\text { dibatasi oleh bentuk geometris yang } \\
\text { kaku. }\end{array}$ & \\
\hline 2. & $\begin{array}{l}\text { Asymmetry and } \\
\text { Dissonance }\end{array}$ & $\begin{array}{l}\text { Door and Picture } \\
\text { Position }\end{array}$ & $\begin{array}{l}\text { Pintu dan frame gambar diletakkan } \\
\text { asimetris pada sebuah bidang. }\end{array}$ & 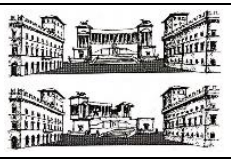 \\
\hline
\end{tabular}




\begin{tabular}{|c|c|c|c|c|}
\hline No. & Konsep & Elemen & Deskripsi & Ilustrasi \\
\hline & & $\begin{array}{l}\text { Pencahayaan atau } \\
\text { bukaan }\end{array}$ & $\begin{array}{l}\text { Cara membuat bukaan atau } \\
\text { pencahayaan alami menghindari di } \\
\text { tengah bidang, tapi lebih baik di } \\
\text { pinggir atau sudut, atau palel pada } \\
\text { bidang yang sama. }\end{array}$ & ma \\
\hline 3. & $\begin{array}{l}\text { Antiperspective } \\
\text { Three- } \\
\text { Dimensionality }\end{array}$ & Perspektif ruang & $\begin{array}{l}\text { Menghindari bentuk simetris pada } \\
\text { bentuk ruang dalam sudut pandang } \\
\text { perspektifis. }\end{array}$ & 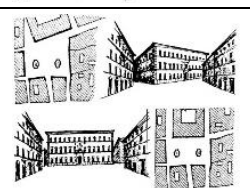 \\
\hline 4. & $\begin{array}{l}\text { The syntax of } \\
\text { Four-dimensional } \\
\text { Decomposition }\end{array}$ & $\begin{array}{l}\text { Bidang-bidang } \\
\text { pelingkup }\end{array}$ & $\begin{array}{l}\text { Bidang-bidang pelingkup ruangan } \\
\text { dipecah dari bentuk box sehingga } \\
\text { terdiri dari enam bidang lepas yang } \\
\text { sambungan diantaranya diredefinisi } \\
\text { ulang. }\end{array}$ & 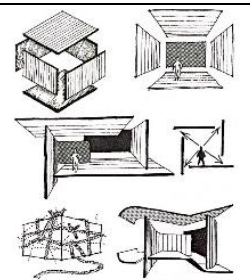 \\
\hline 5. & $\begin{array}{l}\text { Cantilever, Shell, } \\
\text { and Membrane } \\
\text { Structures }\end{array}$ & Struktur & $\begin{array}{l}\text { Hubungan antara bidang pelingkup } \\
\text { dan strukturnya tidak harus } \\
\text { berimpitan. Lebih berani dalam } \\
\text { penggunaan sistem struktur baru } \\
\text { seperti kantilever, shell dan membran } \\
\text { serta bentuknya yang mendobrak } \\
\text { bentuk box klasik. }\end{array}$ & 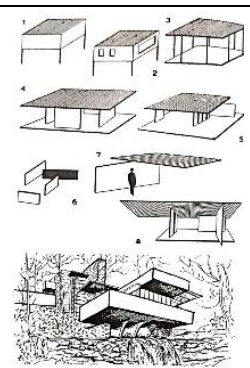 \\
\hline 6. & Space in Time & Sirkulasi & $\begin{array}{l}\text { Menciptakan sirkulasi yang dinamis, } \\
\text { tidak terbatas dalam bentuk ruang } \\
\text { seperti box. }\end{array}$ & IfIn \\
\hline 7. & $\begin{array}{l}\text { Reintergration of } \\
\text { Building, City, and } \\
\text { Landscape }\end{array}$ & $\begin{array}{l}\text { Konseksi, } \\
\text { sirkulasi, } \\
\text { penataan massa }\end{array}$ & $\begin{array}{l}\text { Membuat wadah untuk mixed-use } \\
\text { yang saling berhubungan satu sama } \\
\text { lain, sirkulasi menghubungkan } \\
\text { berbagai akses, dan penataan massa } \\
\text { dilakukan dengan saling berintegrasi } \\
\text { satu sama lain, tidak membatasi suatu } \\
\text { fungsi pada zona tertentu, tapi saling } \\
\text { terkoneksi }\end{array}$ & $\frac{\ln ^{2}}{\sqrt{4}}$ \\
\hline
\end{tabular}

Aspek paling utama yang tercermin pada karya arsitektur tersebut adalah dominannya unsur fungsionalisme dalam konsep perancangannya. Bahasa arsitektur modern yang dirumuskan oleh Bruno Zevi mengacu pada pemikiran modernisme yang anti-klasik, sehingga, bahasa arsitektur yang tercermin pada bangunannya selalu bersifat penyelewengan dari order klasik. Arsitektur modern mengedepankan penggunaan teknologi terdepan pada jamannya.

\section{$2.4 \quad$ ARSITEKTUR SUNDA}

Arsitektur Sunda dapat diklasifikasikan langgamnya pada tabel berikut.

Tabel 2. Karakteristik Arsitektur Sunda

\begin{tabular}{|c|c|}
\hline $\begin{array}{c}\text { Jenis Lingkup pada } \\
\text { Arsitektur Sunda }\end{array}$ & Ilustrasi \\
\hline
\end{tabular}




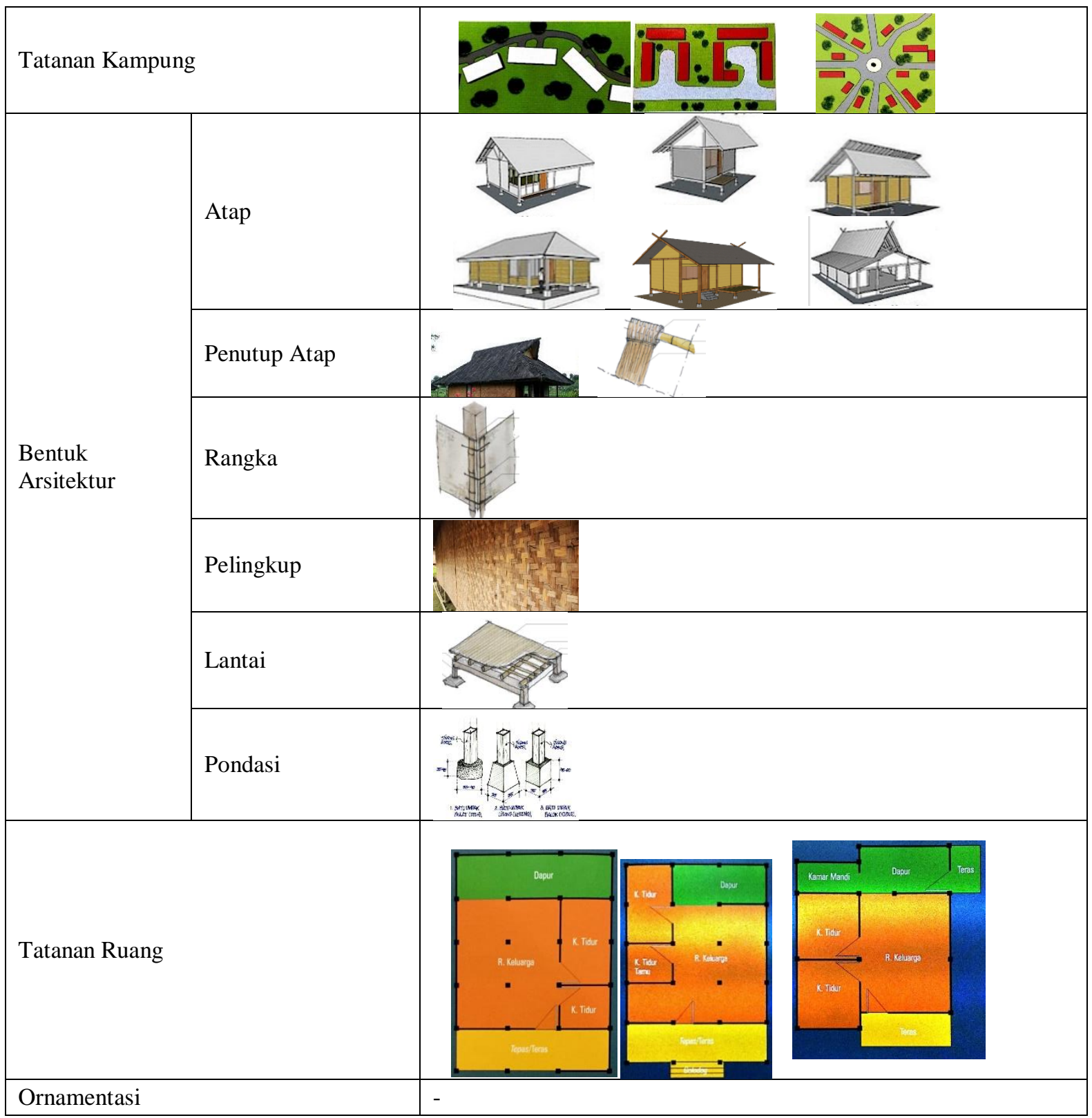

Bentuk tatanan kampung Sunda dapat dilihat dari beberapa order, diantaranya terpusat, linear, maupun radial. Namun, pada dasarnya bentuk kampung pada masa awal berkembang merupakan bentuk organik, kemudian setelah mengalami perkembangan dapat berubah menjadi tatanan yang lebih teratur.

Bentuk arsitektur rumah Sunda dapat dikategorikan menjadi enam jenis berdasarkan bentuk atapnya, yaitu bentuk atap jolopong, tagog anjing, julang ngapak, badak heuay, parahu kumureb, dan capit gunting. Bentuk struktur dan konstruksinya menggunakan material utama bambu yang dirakit menjadi bilik atau bidang yang berpori dengan sambungan ikat atau pasak. Pembagian ruang dalam terbagi menjadi tiga area yang dibagi berdasarkan gender, yaitu area laki-laki (ruang tamu/depan), area perempuan (ruang dapur/belakang), dan area campuran (ruang makan/tengah). 


\section{METODA PENELITIAN}

Jenis penelitian adalah bersifat kualitatif dengan melakukan observasi lapangan terkait aspek bentuk dan makna dengan metode deskriptif analitis interpretatif. Data dijelaskan dengan deskripsi yang kemudian di analisa secara interpretatif berdasarkan hasil observasi, studi literatur dan keserupaan referensi dengan studi literatur terkait.

\section{ANALISA}

\subsection{DESKRIPSI ARSITEKTUR SELASAR SUNARYO ART SPACE}

\subsubsection{DATA UMUM}

Selasar Sunaryo terdiri dari 4 galeri utama yang disewakan untuk pameran para seniman, yaitu Ruang A, Ruang B, Ruang Sayap, dan Bale Tonggoh, serta 2 area pertunjukkan, yaitu amphitheatre dan Bale Handap. Selain itu Selasar Sunaryo mewadahi aktivitas lain seperti tempat istirahat para seniman di Rumah Bambu, cafe Kopi Selasar, serta toko Cinderamata.

Objek studi penelitian adalah kompleks galeri Selasar Sunaryo Art Space yang terletak di Jalan Bukit Pakar Tmur No. 100, Bandung. Lingkup objek penelitian adalah bangunan Galeri Utama (Ruang A dan Ruang B), Galeri Sayap, mushola, toko Cinderamata, beserta lansekapnya termasuk amphitheater.

\begin{tabular}{|l|l|}
\hline Nama Bangunan & Selasar Sunaryo Art Space \\
\hline Fungsi & Galeri Seni, Pusat Komunitas Seni, Cafe \\
\hline Client & Sunaryo \\
\hline Lokasi & Jalan Bukit Pakar Timur No. 100, Bandung 40188, Indonesia \\
\hline Arsitek & Baskoro Tedjo \\
\hline Tahun Dibangun & 1993 \\
Tahun Dibuka & 1998 \\
\hline Luas Tanah & $5000 \mathrm{~m}^{2}$ \\
\hline Luas Bangunan & $500 \mathrm{~m}^{2}$ \\
\hline
\end{tabular}

\subsubsection{KONSEP PERANCANGAN}

Selasar Sunaryo merupakan desain kolaborasi antara arsitek dengan klien. Terdapat tiga syarat dari klien dalam konse perancangan bangunan ini yang dijelaskan pada tabel berikut.

Tabel 3. Konsep Perancangan Selasar Sunaryo

\begin{tabular}{|l|l|l|}
\hline No. & Konsep & Penerapan \\
\hline 1. & $\begin{array}{l}\text { Bangunan harus didesain dengan fungsi } \\
\text { yang bagus sebagai tempat menampilkan } \\
\text { karya-karya seninya. }\end{array}$ & $\begin{array}{l}\text { Konsep sirkulasi pada bangunan dibuat } \\
\text { seperti labirin. } \\
\text { Dinding polos }\end{array}$ \\
\hline 2. & $\begin{array}{l}\text { Seluruh desainnya harus menggunakan } \\
\text { elemen-elemen arsitektur khas Jawa } \\
\text { Barat. }\end{array}$ & $\begin{array}{l}\text { Menggunakan 3 unsur lansekap Jawa Barat: } \\
1 . \quad \text { Tanaman Bambu } \\
\text { 2. Bangunan Panggung } \\
\text { Balong / kolam }\end{array}$ \\
\hline 3. & $\begin{array}{l}\text { Desainnya harus secara mutlak } \\
\text { merepresentasikan karakter dan identitas } \\
\text { karya-karya Sunaryo. }\end{array}$ & $\begin{array}{l}\text { Bentuk geometris tegas dan garis kasar } \\
\text { "Almost zero ornament" }\end{array}$ \\
\hline
\end{tabular}




\subsection{ANALISA AKULTURASI ARSITEKTUR PADA SELASAR SUNARYO ART SPACE}

\subsubsection{AKULTURASI ARSITEKTUR PADA PENELITIAN}

Berdasarkan teori jenis akulturasi, terdapat tiga jenis akulturasi yang relevan dengan penelitian ini, yaitu sintesis, adopsi, dan adaptasi. Suatu komponen arsitektur dapat dikatakan merupakan hasil sintesis arsitektur apabila propertinya berbeda dengan pendahulunya dan susunannya juga berbeda dengan pendahulunya. Artinya, komponen arsitektur tersebut telah menggabungkan dua atau lebih unsurnya dan menghasilkan sesuatu yang baru. Suatu komponen dikatakan merupakan hasil adaptasi arsitektur apabila salah satu diantara properti dan susunannya memiliki kesamaan dengan pendahulunya, dan yang lainnya berbeda dengan pendahulunya. Artinya, komponen arsitektur tersebut melakukan sebagian besar penggabungan dua atau lebih unsurnya tapi tidak menghasilkan sesuatu yang baru. Suatu komponen dikatakan merupakan hasil adopsi arsitektur apabila properti dan susunannya sama dengan pendahulunya. Artinya, komponen arsitektur tersebut melakukan sedikit penggabungan dua atau lebih unsurnya dan tidak menghasilkan sesuatu yang baru. Tabel dibawah menjelaskan relasi antara jenis akulturasi dengan properti serta susunan komponen arsitekturnya.

Tabel 4. Relasi Bahasa Arsitektur dengan Akulturasi dalam Arsitektur

\begin{tabular}{|c|c|c|c|}
\hline \multirow{2}{*}{$\begin{array}{c}\text { Jenis } \\
\text { Akulturasi }\end{array}$} & \multicolumn{2}{|c|}{ Komponen Arsitektur } & \multirow[t]{2}{*}{ Hasil } \\
\hline & Properti & Susunan & \\
\hline Sintesis & $\begin{array}{l}\text { Berbeda dengan } \\
\text { pendahulunya }\end{array}$ & $\begin{array}{l}\text { Berbeda dengan } \\
\text { pendahulunya }\end{array}$ & $\begin{array}{l}\text { Menghasilkan sesuatu yang } \\
\text { baru } \\
\text { Contoh: Aula ITB }\end{array}$ \\
\hline \multirow[t]{2}{*}{ Adaptasi } & $\begin{array}{l}\text { Berbeda dengan } \\
\text { pendahulunya }\end{array}$ & $\begin{array}{l}\text { Sama dengan } \\
\text { pendahulunya }\end{array}$ & \multirow{2}{*}{$\begin{array}{l}\text { Melakukan sebagian besar } \\
\text { penggabungan unsur tapi } \\
\text { tidak menghasilkan suatu } \\
\text { bentuk atau nilai yang baru } \\
\text { Contoh : Lawang Sewu }\end{array}$} \\
\hline & Sama dengan pendahulunya & $\begin{array}{l}\text { Berbeda dengan } \\
\text { pendahulunya }\end{array}$ & \\
\hline Adopsi & Sama dengan pendahulunya & $\begin{array}{l}\text { Sama dengan } \\
\text { pendahulunya }\end{array}$ & $\begin{array}{l}\text { Melakukan percampuran } \\
\text { unsur tapi tidak menghasilkan } \\
\text { suatu bentuk atau nilai yang } \\
\text { baru. } \\
\text { Contoh : Gedung Mahkamah } \\
\text { Konstitusi Indonesia }\end{array}$ \\
\hline
\end{tabular}

\subsubsection{ANALISA PENERAPAN AKULTURASI PADA LINGKUP TAPAK}

\section{a. Penataan Massa}

Massa-massa pada tapak memiliki penataan yang memiliki ketinggian yang berbedabeda. Penataan massa bangunan disesuaikan dengan bentuk kontur tanah pada tapak. Pada tapak, terdapat 3 karakteristik elemen kampung Sunda, namun susunan pada tapak menunjukkan campuran antara penataan kampung Sunda dengan gaya modern. 


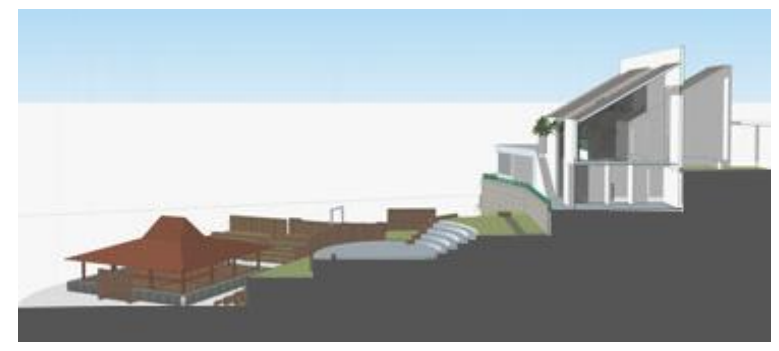

Gambar 1. Penataan massa pada Selasar Sunaryo yang menyikapi bentuk kontur

\section{b. Karakteristik Lansekap}

Pada selasar sunaryo terdapat 3 karakteristik utama yang terdapat pada lansekap kampung adat Sunda, yaitu elemen air, elemen hutan keramat, dan kontur tanah yang berundak. Elemen air ditandai dengan kolam-kolam yang diletakkan di depan massa galeri utama dan galeri sayap. Elemen hutan keramat terdapat pada area tidak terbangun di dekat mushola, dan ditandai dengan banyaknya ditanami pohon bambu di berbagai titik lansekap Selasar Sunaryo, sebagaimana pohon bambu merupakan pohon yang banyak ditemukan di lansekap Jawa Barat. Serta suasana kontur yang berundak, ditekankan dengan penempatan massa bangunan yang disesuaikan dengan tinggi kontur, serta sirkulasi sepanjang lansekap yang berundak. Namun, cara menyusun ketiga elemen tersebut dilakukan dengan gaya modern dan tidak membawa fungsi atau makna lansekap kampung Sunda.

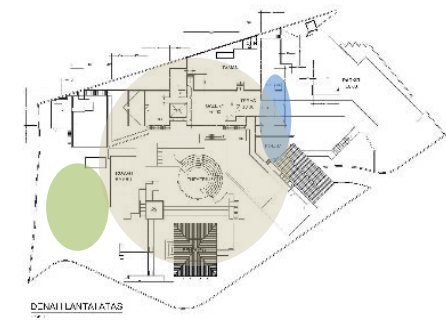

Area elemen air

Area elemen pepohonan

Area kontur berundak

Gambar 2. Peta Kunci Penataan Tapak

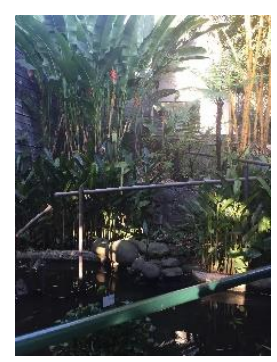

Gambar 3. Elemen Kolam

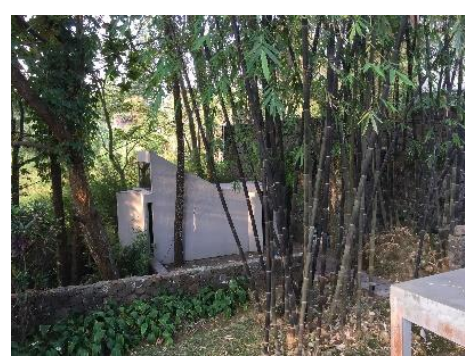

Gambar 4. Elemen tanaman bambu

\section{c. Amphitheater}

Properti yang terdapat pada amphitheater menunjukkan konsep fungsi performance art, seperti yang dilakukan pada tempat pertunjukkan seni nusantara, dilakukanpada ruangan terbuka, dipadukan dengan konsep amphitheater pada arsitektur Roma purba. Material yang digunakan merupakan material lokal yang dipadukan dengan cara menyusun gaya modern, yaitu material semen dengan warna abu-abu. 


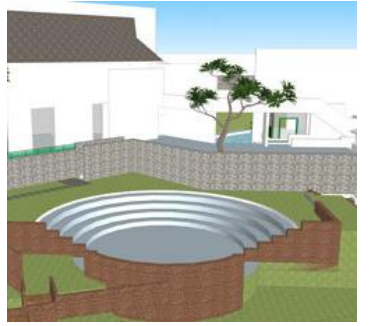

Gambar 5. Amphitheater di Selasar Sunaryo

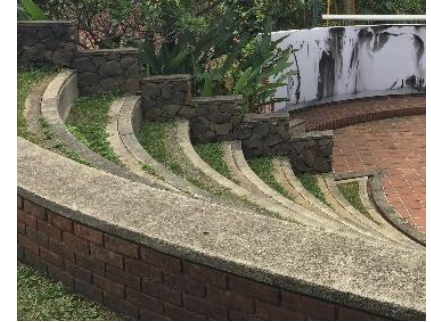

Gambar 6. Material di amphitheater

\subsection{ANALISA PENERAPAN AKULTURASI PADA LINGKUP BENTUK}

a. Massa Utama

Properti gubahan tiga dimensi menunjukkan bentuk dasar limas trapesium, seperti percampuran bentuk dasar arsitektur Sunda dan modern. Susunan propertinya terlihat modern ditinjau dari dinding polos yang besar yang menegaskan aksis bangunan dan tidak menerapkan konsep pola-tiga sebagaimana pada arsitektur Sunda.
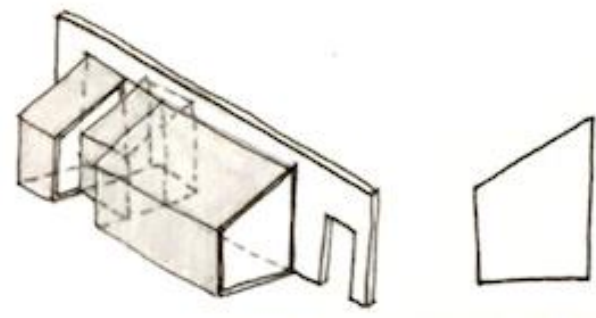

Gambar 7. Bentuk 3D Massa Utama

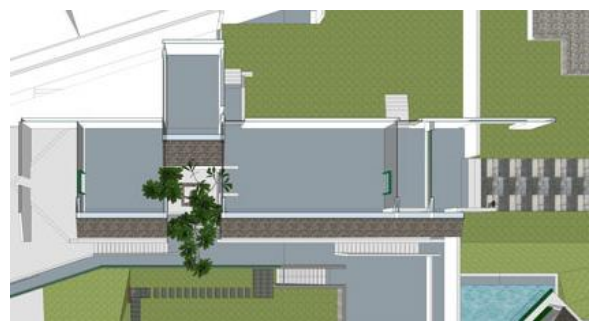

Gambar 8. Denah lantai atas massa utama

Pada bangunan ini atap tidak berfungsi melindungi dinding dari paparan hujan dan matahari namun bentuknya menunjukkan siluet atap Sunda, julang ngapak, yang dikonstruksikan secara modern. Elemen badan bangunan berupa dinding-dinding polos yang disusun seolah terurai menunjukkan karakter modern dengan susunan modern yang menghindari suasana order klasik atau kaku dari dalam ruangan. Selain itu terdapat satu bagian bangunan yang terlihat disusun secara menyimpang dari aksis utama bangunan yang menunjukkan karakteristik bangunan modern. Properti dan susunan lantai terlihat modern, terlihat dari konstruksinya yang menapak tanah dan tidak menerapkan konsep panggung.

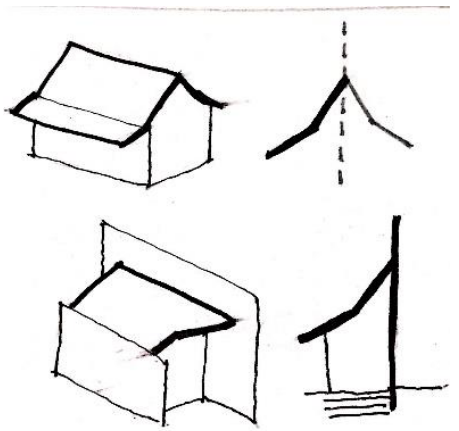

Gambar 9. Bentuk Atap Massa Utama

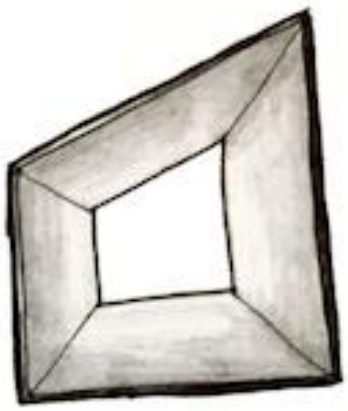

Gambar 10. Bentuk Badan Massa Utama 


\section{b. Massa Sayap}

Properti gubahan tiga dimensi menunjukkan bentuk dasar limas trapezium, seperti percampuran bentuk dasar arsitektur Sunda dan modern. Susunan propertinya terlihat modern ditinjau dari dinding polos yang besar yang menegaskan aksis bangunan dan tidak menerapkan konsep pola-tiga sebagaimana pada arsitektur Sunda.

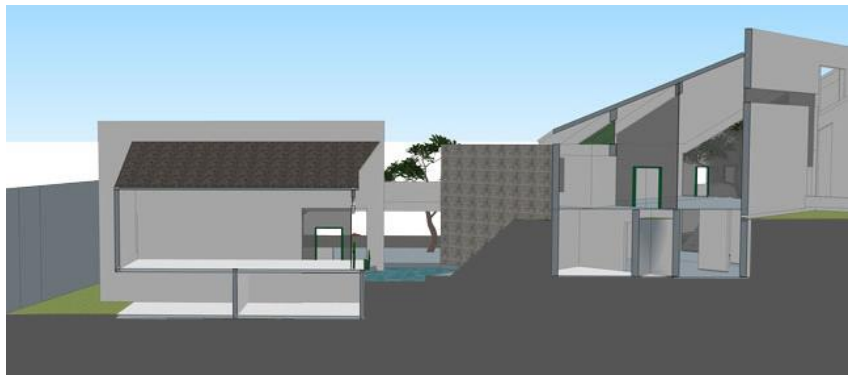

Gambar 11. Massa sayap pada tapaknya

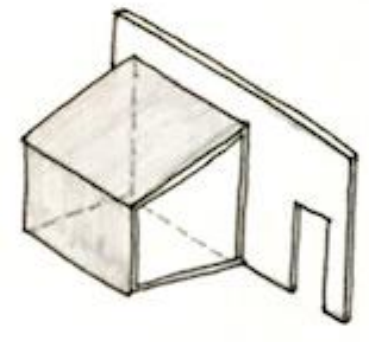

Gambar 12. Bentuk dasar massa sayap

Pada bangunan ini atap tidak berfungsi melindungi dinding dari paparan hujan dan matahari namun bentuknya menunjukkan siluet atap Sunda, julang ngapak, yang dikonstruksikan secara modern. Elemen badan bangunan berupa dinding-dinding polos yang disusun seolah terurai menunjukkan karakter modern dengan susunan modern yang menghindari suasana order klasik atau kaku dari dalam ruangan. Terdapat konsep elemen panggung dan air/kolam pada bagian lantai bangunan namun susunannya menunjukkan konstruksi modern.
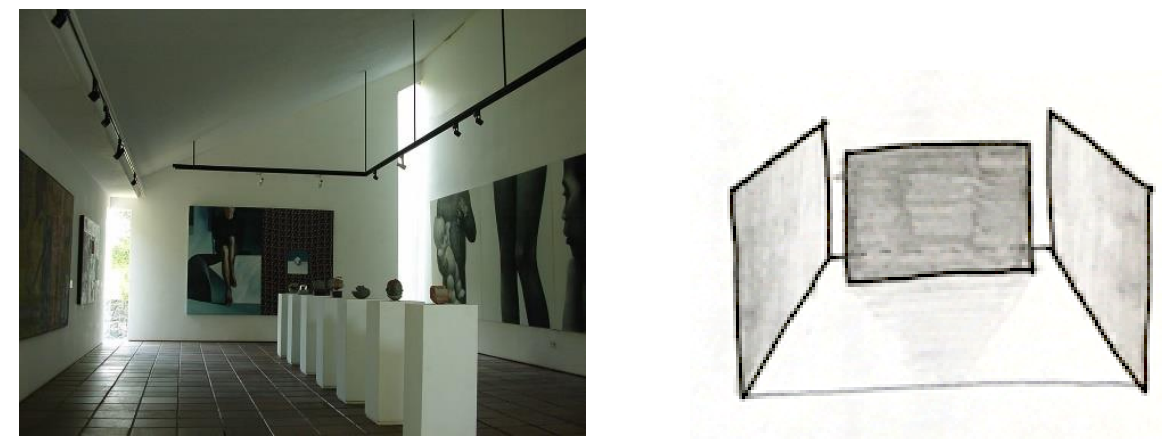

Gambar 13. Jendela dan pencahayaan alami pada ruang sayap

Gambar 14. Ilustrasi penataan bidang pada massa sayap

\section{c. Massa Mushola}

Properti gubahan tiga dimensi menunjukkan bentuk dasar volume persegi panjang yang diadisi dan substraksi di beberapa bagian, menunjukkan karakter bentuk dasar arsitektur modern. Susunan propertinya terlihat modern ditinjau dari dinding polos dan tidak menerapkan konsep pola-tiga sebagaimana pada arsitektur Sunda.

Pada bangunan ini atap tidak berfungsi melindungi dinding dari paparan hujan dan matahari namun bentuknya menunjukkan gabungan siluet atap Sunda dan modern yang dikonstruksikan secara modern. Elemen badan bangunan berupa dinding-dinding polos yang 
disusun seolah terurai menunjukkan karakter modern dengan susunan modern yang menghindari suasana order klasik atau kaku dari dalam ruangan.

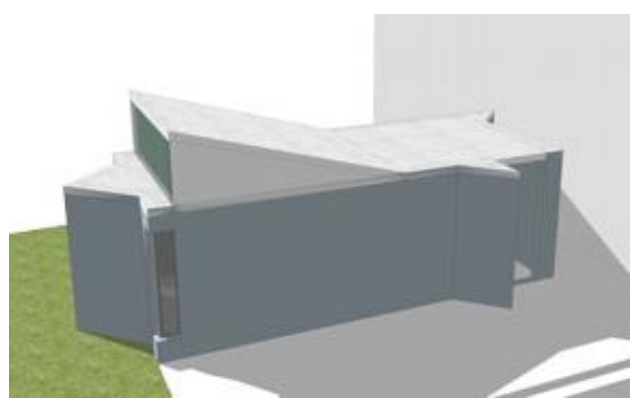

Gambar 15. Bentuk 3D massa mushola

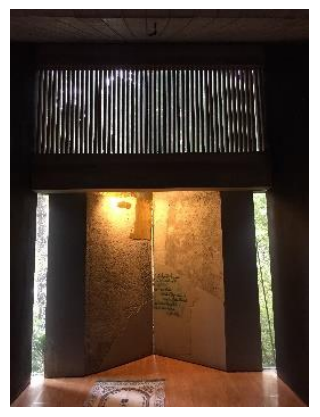

Gambar 16. Kisi-kisi pada mushola

\section{d. Massa Cinderamata}

Properti gubahan tiga dimensi menunjukkan bentuk dasar persegi yang terdapat beberapa substraksi, menunjukkan bentuk arsitektur modern. Susunan propertinya terlihat modern ditinjau dari dinding polos dan tidak menerapkan konsep pola-tiga sebagaimana pada arsitektur Sunda.

Pada bangunan ini atap tidak berfungsi melindungi dinding dari paparan hujan dan matahari. Elemen badan bangunan berupa dinding polos dan terdapat substraksi yang menunjukkan karakter modern dengan susunan modern yang menghindari suasana order klasik atau kaku dari dalam ruangan.

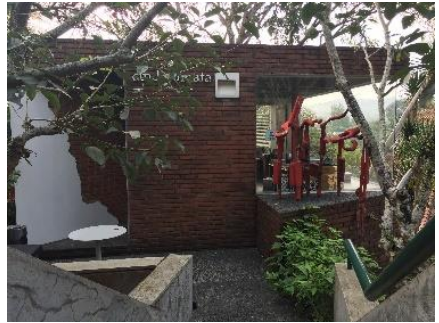

Gambar 17. Bagian depan Cinderamata

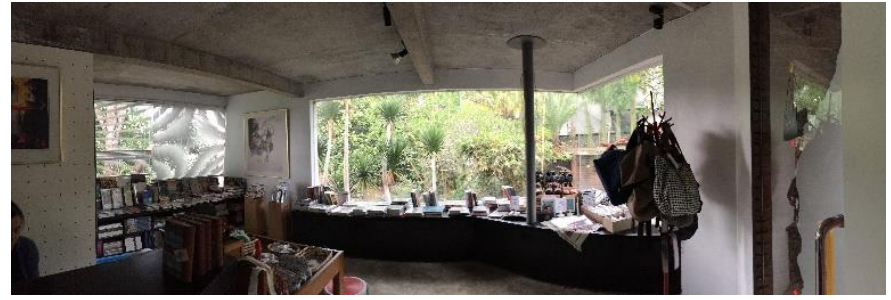

Gambar 18. Pengaruh letak jendela pada suasana ruang dalam cinderamata

\subsection{ANALISA PENERAPAN AKULTURASI PADA LINGKUP SOSOK}

\section{a. Massa Utama}

Barrier berupa dinding-dinding polos yang berfungsi agar tidak mendominasi karya seni yang dipajang di dalam galeri. Filter berupa jendela besar dan kisi-kisi. Kisi-kisi tidak berfungsi sebagai ventilasi udara seperti pada bangunan tradisional, sehingga hanya melayani efek visual saja.

Penyusunan dinding dibuat agar menciptakan efek box yang diurai sehingga menciptakan suasana dan order di dalam ruang yang tidak kaku. Penempatan jendela kaca di sudut-sudut ruangan membantu menciptakan efek ini. Secara keseluruhan properti dan susunan bangunan adalah modern. 


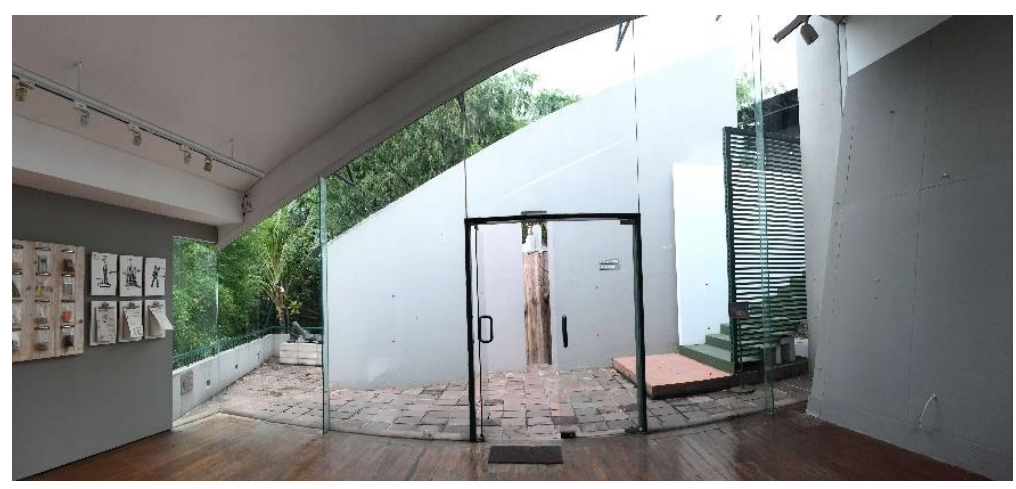

Gambar 19. Komposisi filter dan barrier: jendela dan dinding pada massa utama

\section{b. Massa Sayap}

Bentuk keseluruhan bangunan terdiri dari susunan barrier bidang-bidang polos, fungsinya agar latar belakang tempat memajang benda pameran tidak lebih mencolok dari karya seni yang dipamerkan sendiri. Pada sisi yang menghadap utara, dinding menggunakan filter berupa kaca sehingga cahaya alami dapat masuk ke dalam bangunan. Terdapat filter berupa kisi-kisi di bagian depan bangunan, seperti pada bangunan tradisional dimana kisi-kisi ini berfungsi sebagai ventilasi.

Penyusunan dinding dibuat agar menciptakan efek box yang diurai sehingga menciptakan suasana dan order di dalam ruang yang tidak kaku. Penempatan jendela kaca di sudut-sudut ruangan dan dinding kaca polos floor-to-ceiling pada sisi bangunan yang menghadap utara membantu menciptakan efek ini.

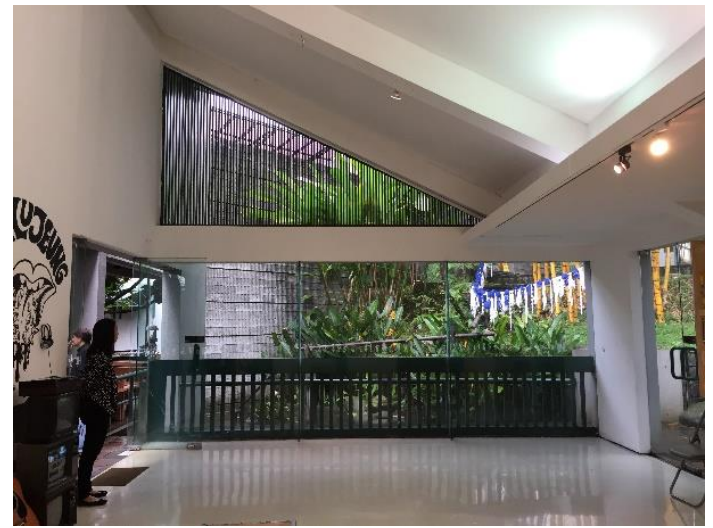

Gambar 20. Relasi jendela dengan pemandangan di luar ruang

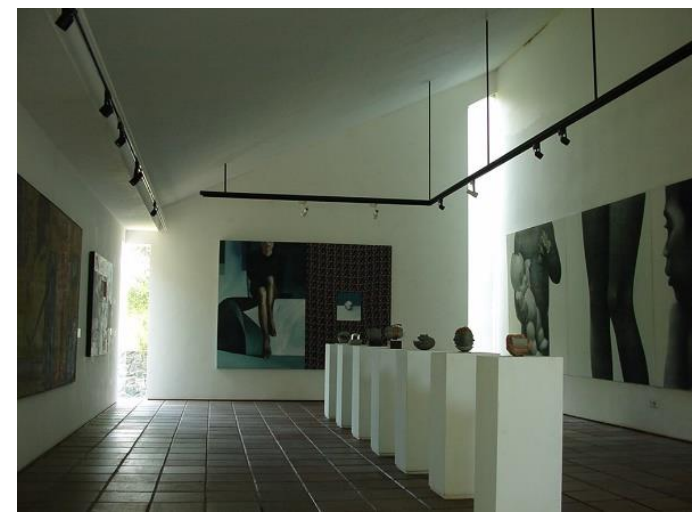

Gambar 21. Penyusunan dinding dan jendela pada massa sayap

\section{c. Massa Mushola}

Secara keseluruhan dinding bangunan dibiarkan polos, kecuali pada dinding yang menghadap kiblat terdapat kaligrafi, serta dinding yang terdapat di sisi belakang dibiarkan menjadi dinding bata ekspos dengan menggunakan beberapa glass-box. Terdapat kisi-kisi besi di atap, namun tidak berfungsi sebagai ventilasi sebagaimana yang terdapat pada kisi-kisi bangunan tradisional karena pada sisi luarnya ditutup oleh kaca. Namun kisi-kisi tersebut memfilter cahaya membuat cahaya di dalam ruang terlihat lebih redup.

Kaca diletakkan di sudut ruangan sehingga dinding yang menghadap kiblat terlihat terlepas dari dinding lainnya. Kaca lebih berfungsi sebagai sumber cahaya dibanding sebagai 
inlet frame pemandangan yang terdapat di luar bangunan. Glass-box yang terdapat di dinding bagian belakang pula berfungsi sebagai inlet sumber cahaya alami. Kisi-kisi di atap juga berfungsi sebagai sumber cahaya alami, namun keberadaan kisi-kisi menyebabkan suatu efek pencahayaan tertentu seperti yang ditemukan pada kisi-kisi rumah tradisional.

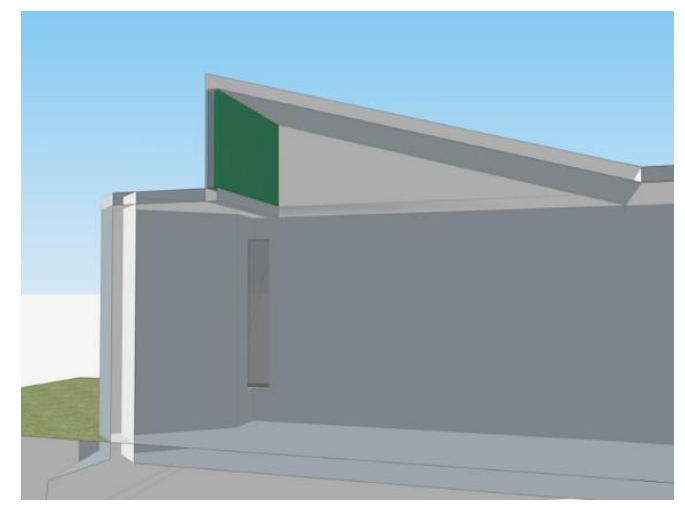

Gambar 22. Komposisi dinding, jendela dan kisi-kisi pada ruang dalam mushola

\section{d. Massa Cinderamata}

Dinding pelingkup Cinderamata terdiri dari dinding-dinding massif kecuali jendela kaca dan pintu kaca. Konstruksi kusen kaca dan pintu kaca dibuat minimalis sehingga tidak terlihat adanya ornamentasi. Jendela kaca mati menyajikan pemandangan terhadap ruangan luar.

Dinding massif menciptakan kesan ruangan kubus. Jendela kaca terletak di sudut sehingga kesan ruangan kubus terasa "bocor" pada ruang luar sehingga terasa adanya interaksi visual antara ruang dalam dan ruang luar. Posisi pintu yang menyerong menciptakan suasana ruang yang tidak kaku.

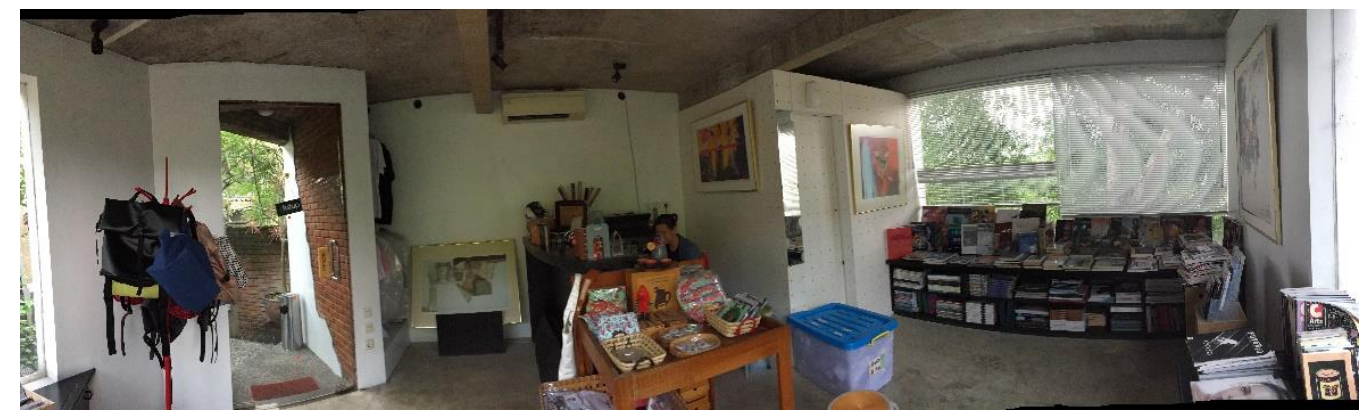

Gambar 23. Ruang dalam massa cinderamata

\subsection{PENERAPAN AKULTURASI ARSITEKTUR PADA SELASAR SUNARYO}

Hasil analisa properti dan susunan pada lingkup tapak, bentuk dan sosok Selasar Sunaryo dirangkum pada tabel dibawah untuk dinilai jenis akulturasi yang terjadi pada arsitektur Selasar Sunaryo.

Tabel 4.1 Penerapan Akulturasi Arsitektur pada Selasar Sunaryo 


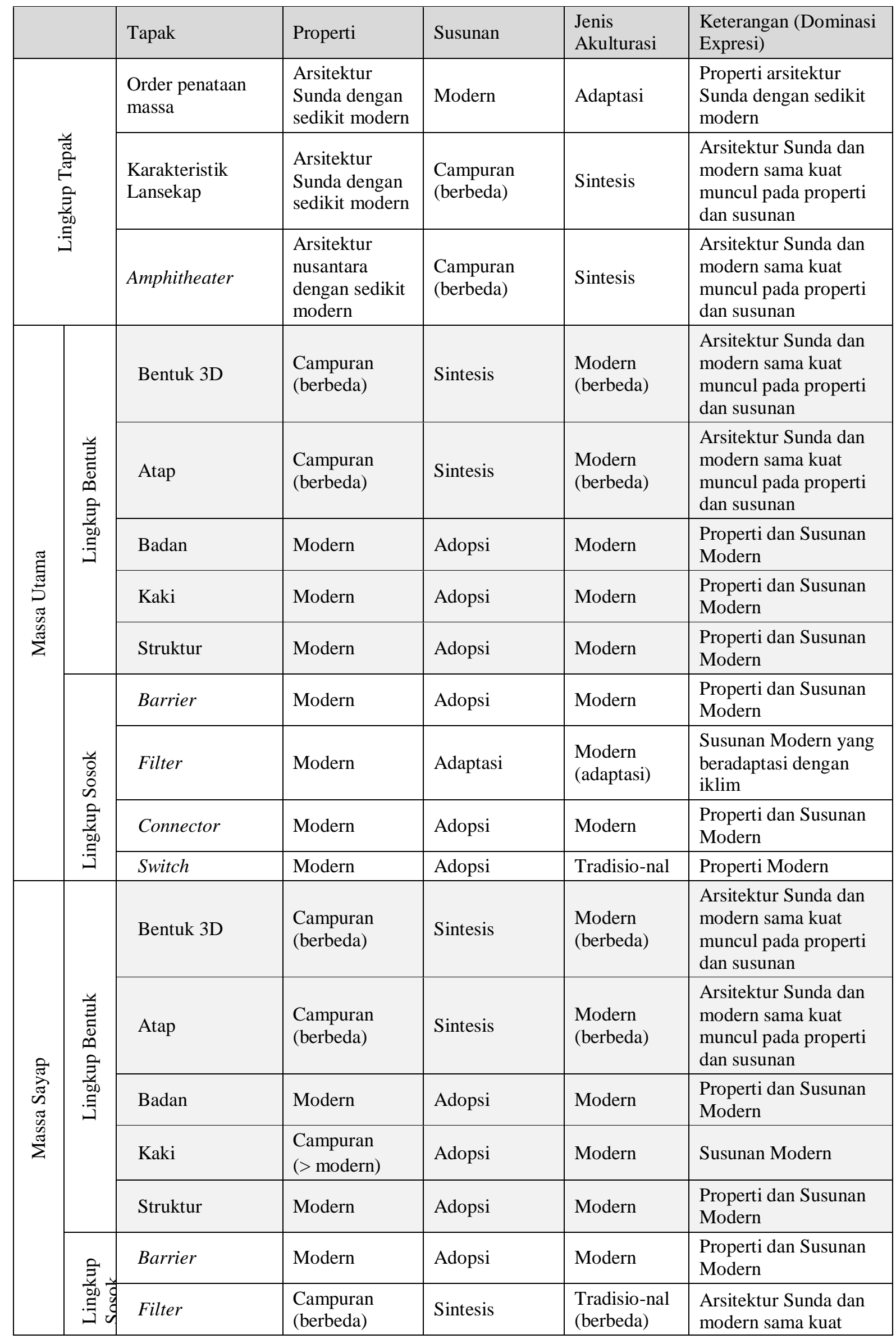




\begin{tabular}{|c|c|c|c|c|c|c|}
\hline & Tapak & Properti & Susunan & $\begin{array}{l}\text { Jenis } \\
\text { Akulturasi }\end{array}$ & $\begin{array}{l}\text { Keterangan (Dominasi } \\
\text { Expresi) }\end{array}$ \\
\hline & & & & & & $\begin{array}{l}\text { muncul pada properti } \\
\text { dan susunan }\end{array}$ \\
\hline & & Connector & Modern & Adopsi & Modern & $\begin{array}{l}\text { Properti dan Susunan } \\
\text { Modern }\end{array}$ \\
\hline & & Switch & Modern & Adopsi & Modern & $\begin{array}{l}\text { Properti dan Susunan } \\
\text { Modern }\end{array}$ \\
\hline \multirow{9}{*}{ 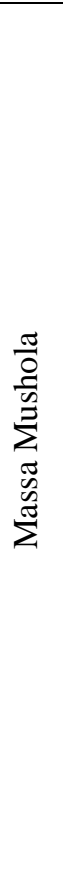 } & \multirow{5}{*}{ 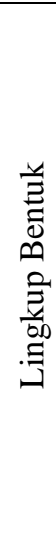 } & Bentuk 3D & $\begin{array}{l}\text { Campuran } \\
\text { (berbeda) }\end{array}$ & Sintesis & $\begin{array}{l}\text { Modern } \\
\text { (berbeda) }\end{array}$ & $\begin{array}{l}\text { Arsitektur Sunda dan } \\
\text { modern sama kuat } \\
\text { muncul pada properti } \\
\text { dan susunan }\end{array}$ \\
\hline & & Atap & $\begin{array}{l}\text { Campuran } \\
\text { (> modern) }\end{array}$ & Adopsi & Modern & Susunan Modern \\
\hline & & Badan & Modern & Adopsi & Modern & $\begin{array}{l}\text { Properti dan Susunan } \\
\text { Modern }\end{array}$ \\
\hline & & Kaki & Modern & Adopsi & Modern & $\begin{array}{l}\text { Properti dan Susunan } \\
\text { Modern }\end{array}$ \\
\hline & & Struktur & Modern & Adopsi & Modern & $\begin{array}{l}\text { Properti dan Susunan } \\
\text { Modern }\end{array}$ \\
\hline & \multirow{4}{*}{ 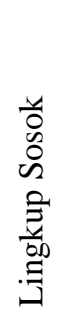 } & Barrier & Modern & Adopsi & Modern & $\begin{array}{l}\text { Properti dan Susunan } \\
\text { Modern }\end{array}$ \\
\hline & & Filter & Modern & Adopsi & Modern & $\begin{array}{l}\text { Properti dan Susunan } \\
\text { Modern }\end{array}$ \\
\hline & & Connector & - & - & - & - \\
\hline & & Switch & Modern & Adopsi & Modern & $\begin{array}{l}\text { Properti dan Susunan } \\
\text { Modern }\end{array}$ \\
\hline \multirow{9}{*}{ 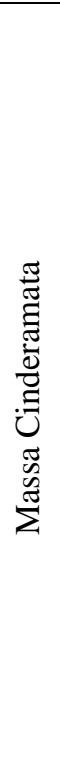 } & \multirow{5}{*}{ 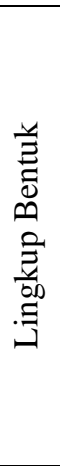 } & Bentuk 3D & Modern & Adopsi & Modern & $\begin{array}{l}\text { Properti dan Susunan } \\
\text { Modern }\end{array}$ \\
\hline & & Atap & Modern & Adopsi & Modern & $\begin{array}{l}\text { Properti dan Susunan } \\
\text { Modern }\end{array}$ \\
\hline & & Badan & Modern & Adopsi & Modern & $\begin{array}{l}\text { Properti dan Susunan } \\
\text { Modern }\end{array}$ \\
\hline & & Kaki & Modern & Adopsi & Modern & $\begin{array}{l}\text { Properti dan Susunan } \\
\text { Modern }\end{array}$ \\
\hline & & Struktur & Modern & Adopsi & Modern & $\begin{array}{l}\text { Properti dan Susunan } \\
\text { Modern }\end{array}$ \\
\hline & \multirow{4}{*}{ 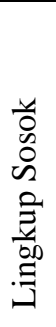 } & Barrier & Modern & Adopsi & Modern & $\begin{array}{l}\text { Properti dan Susunan } \\
\text { Modern }\end{array}$ \\
\hline & & Filter & Modern & Adopsi & Modern & $\begin{array}{l}\text { Properti dan Susunan } \\
\text { Modern }\end{array}$ \\
\hline & & Connector & - & - & - & - \\
\hline & & Switch & Modern & Adopsi & Modern & $\begin{array}{l}\text { Properti dan Susunan } \\
\text { Modern }\end{array}$ \\
\hline
\end{tabular}

\section{KESIMPULAN}

Dari hasil analisa ditemukan bahwa sebagian besar aspek bangunan dari massa-massa yang diteliti mengadopsi gaya modern. Percampuran gaya berupa sintesis paling banyak dilakukan pada elemen atap dan tapak, namun pada elemen badan, lantai, struktur dan pada lingkup sosok sangat terlihat dominasi modernisme. 
Sintesis yang dilakukan pada elemen atap adalah dengan mengambil ekspresi bentuk atap arsitektur Sunda kemudian disusun dengan konstruksi yang modern. Namun, elemen atap tidak berfungsi sebagaimana atap pada bangunan tradisional yang di antaranya berfungsi sebagai elemen ventilasi udara bangunan lewat materialnya yang berongga serta teritisnya yang panjang melindungi material dinding dari paparan air hujan dan matahari yang ekstrim.

Hal yang sama dilakukan pada tapak, yatu mengambil properti arsitektur Sunda di antaranya elemen pepohonan, air atau kolam dan tanah berundak, namun fungsi dari ketiga elemen tersebut tidak diterapkan pada Selasar Sunaryo. Di antaranya adanya area lahan yang sengaja tidak dibangun untuk mempertahankan rasio lahan terbangun dengan yang tidak agar menjaga keseimbangan kondisi tanah, tapi tidak benar-benar bersifat sakral sebagaimana hutan terlarang pada kampung Sunda, juga tidak menjadi sumber kebutuhan sehari-hari pada siklus aktivitas Selasar Sunaryo. Demikian pula dengan elemen kolam yang hanya berfungsi sebagai elemen hiasan dan tidak difungsikan untuk berternak ikan atau mencuci.

Akulturasi yang berusaha ditampilkan pada Selasar Sunaryo yaitu dengan menyertakan konsep arsitektur Sunda pada bangunan modern merupakan salah satu usaha untuk mempertahankan keberlangsungan karakter arsitektur lokal di tengah arus perkembangan jaman. Namun akan lebih baik kalau penerapan konsep arsitektur lokal tidak hanya ditampilkan dalam aspek bentuk saja namun juga mewadahi fungsi yang fungsional sesuai budaya dan iklim setempat. Contohnya pada elemen atap, tidak hanya meniru bentuk atau ekspresinya saja yang diambil namun lebih baik juga kalau benar-benar melindungi bangunan, terutama dinding eksterior dan sirkulasi atau membantu melancarkan sirkulasi udara sebagaimana fungsi atap pada arsitektur Sunda.

\section{DAFTAR PUSTAKA}

\section{Jurnal}

Darkim, B. (2013). Perancangan Galeri Seni Bilah Nusantara dengan Penerapan Arsitektur Jawa di Sleman, Yogyakarta. Malang: Universitas Brawijaya https://www.academia.edu/6468610/PERANCANGAN_GALERI_SENI_BILAH_NUSANTA RA_DENGAN_PENERAPAN_ARSITEKTUR_JAWA_DI_SLEMAN_YOGYAKARTA_JU RNAL_ILMIAH

Deny, M. (2007). Rumah Tradisional Sunda dalam Perspektif Teori Paradoks. Bandung: Universitas Kristen Maranatha

Kustianingrum, D. Et al. (2013). Kajian Penataan Massa dan Tipologi Bentuk Bangunan Kampung Adat Dukuh di Garut. Bandung: Institut Teknologi Nasional

Salura, P. (2012). Sintesis Elemen Arsitektur Lokal dengan Non-Lokal, Kasus studi : Gedung Sate di Bandung, Gedung UPS di Tegal. Bandung: Universitas Katolik Parahyangan

\section{Buku}

Anwar, H \& Nugraha, H. A. (2013). Rumah Etnik Sunda. Jakarta: Griya Kreasi.

Ching, F. D. K. (1943). Form, Space and Order. New Jersey: John Wiley \& Sons, Inc.

Salura, P. (2015). Arsitektur yang Membodohkan. Jakarta : Gakushudo Publisher.

Tedjo, B. (2013). Extending Sensibilities Through Design (Architectural Works 1997-2012). Jakarta: PT. Imaji Media Pustaka

Thiis-Evensen, T. (1987). Archetypes in Architecture. Oxford: Norwegian University Press.

Zevi, B. (1978). Modern Language of Architecture. Seattle : University of Washington Press 